academic community resists change, the greater is the risk of losing support from society, and therefore of the flowering of private, profit-making universities. This will have severe consequences for science. Eurico C. de Oliveira

Instituto de Biociencias, Universidade de São Paulo, Cpostal 11461, 05422-970 São Paulo, SP, Brasil

\section{Scientists at the sharp end in a disaster zone}

Sir - In a News item (Nature 392, 743-744; 1998), you discuss the role of scientists in the management of the Montserrat volcano crisis, on the basis of the verbal presentation of an unpublished study at a meeting.

This study appears to rely mainly on the findings of a student's research project that covered a few months of this prolonged emergency (now nearing three years duration). As far as the Montserrat Volcano Observatory is concerned, the study and visit had no official standing at the time, and was conducted outside the ambit of any of the emergency organizations operating in Montserrat. This work is, as yet, unrevealed for scrutiny and it remains to be seen whether the methods used were robust and reliable, particularly in respect of canvassing accurate opinions from a complex West Indian society under stress. This perspective has been given prominence and currency by your report and, by publishing unsubstantiated assertions about the conduct of the crisis, there is a danger of misleading your readers. On behalf of the scientists who have worked at the observatory throughout the crisis, we reject the main thrust of the piece, and many of its inferences.

Strong emphasis is placed in the report on "predictions" during the eruption, and the ways in which they are purported to have failed. Throughout the crisis, the observatory's scientists have been providing descriptive and probabilistic scenarios of potential eruptive activity over various timescales, using layman's terms as far as possible. They have not, at any time, offered public predictions in any accepted scientific sense of the term. The vast majority of the population developed a sound understanding of the eruption and its implications, and quickly accepted that many aspects of volcanic phenomena are unpredictable.

The examples of supposed predictions cited in the article are either inappropriate or incorrect. For instance, the authorities and the public had been repeatedly advised that explosions, such as that of 17 September 1996, could occur with little or no warning. The heightened alert that accompanied the strong eruptive activity on
19 December 1996 was not a failed prediction. What happened was that observed activity, such as seismicity buildup and ongoing dome collapse, exceeded thresholds for raising the alert level, agreed previously with the civil authorities to indicate a state requiring precautionary evacuation of selected areas. To term this a "false alarm" is tendentious — the warning signs, and official concern, were real and had to be acted upon.

The scientists of the observatory team have provided timely hazard appraisals and detailed risk mitigation strategies, using modern methods of structured assessment, and their work has recently been scrutinized by a House of Commons select committee and by a group chaired by the UK government's chief scientific adviser. In addition to their arduous and often dangerous scientific investigation of the eruption, the team has sustained a public outreach effort probably unsurpassed in any previous volcanic emergency. There is a wealth of documentary evidence about the public's understanding and response to the scientific component of this emergency, which will become increasingly available once the crisis has subsided, and upon which a balanced and complete account of the observatory's contribution to the management of the Montserrat eruption can be based. Only then can successes or shortcomings be rationally judged.

In particular, all the factors surrounding the 19 fatalities on 25 June 1997 (and two others later on) are yet to be fully elucidated and appraised. We wish to stress that scientific warnings had been issued (or acted upon) between December 1996 and June 1997. Although some people had been allowed back into certain areas after the December activity subsided, a reevacuation and extended exclusion zone were implemented well before the big dome collapse occurred. All the casualties occurred within that exclusion zone, in areas that had been clearly identified as high risk. This casualty toll should be placed in its wider context: at the outset of the crisis in July 1995, when many in Montserrat were unaware that the Soufriere Hills was an active volcano, there were about 7,000 people living and working in areas that are now buried by pyroclastic flows or obliterated by violent surges. Their lives were successfully protected, albeit at great personal cost and privation.

In an editorial (Nature 388, 1; 1997), you used the tragic events of 25 June 1997 to enjoin scientists confronting natural disasters to co-operate more closely with social scientists. In principle, this is a sensible proposal, and worthwhile if there is scope for achieving real benefit. But in a free society there will always be individuals who will not heed advice or instructions to avoid hazardous situations such as those on the flanks of an erupting volcano. This was a major factor in the Montserrat fatalities, not the minutiae of communications between scientists and the public. Many people put themselves in danger attempting to convince the victims to leave those areas and, in terms of any scientific function, it is not clear what more could have been done to avert these casualties.

The fact that a significant number of individuals may knowingly choose to accept extreme levels of risk to remain in a danger zone will present a major challenge for societal risk management at volcanoes elsewhere. A careful, collaborative analysis of all the experience from the Montserrat crisis is merited, not a unilateral and illconsidered rush to judgement. Your article and its shortcomings are, therefore, at best unhelpful, and may actually discourage hard-pressed scientists (endeavouring to help protect life and limb) from engaging with colleagues from the social sciences in any similar safety-critical situation.

Willy Aspinall, Peter Francis, Lloyd Lynch, Richard Robertson, Keith Rowley, Steve Sparks, Simon Young and others Montserrat Volcano Observatory, St Johns, Montserrat, West Indies e-mail:mvo@candw.ag

Sir - A recent News story about the earthquake on Montserrat referred to a report with which I was involved (Nature 392, 743-744; 1998). The thrust of our findings was that the scientists involved have been in the unenviable position of $d e$ facto disaster managers, a role for which they were not trained nor, it could be argued, should have been involved in.

There has therefore been an additional burden to their already complex and difficult task of being both authors and messengers of volcanic forecasting and warning. It should be recognized that, if the scientists had not been involved, the death toll on the island would have certainly been higher. Their role has been one of crisis management in extreme circumstances.

It was not part of our findings that many residents felt "the scientists' prediction record was sometimes no better than their own". Although one or two may have held this view, this generalization was not made. The credibility of the scientists has generally been high throughout the crisis; indeed, the constant focus on the scientists' activities would appear to be one of the major contributing pressures on them. The project was funded by the UK Department for International Development as part of a two-year project looking at forecasting and warnings in four parts of the world.

\section{David Sanderson}

154 Banbury Road, Kidlington,

Oxford OX5 2BY, UK 